\title{
Utilization of Horizontal Water System as Electrical Power Generation in Pico Scale with a Small Bulb Turbine
}

\author{
A. Nurdin ${ }^{1 *}$, D. A. Himawanto², S. Hadi ${ }^{2}$ \\ ${ }^{1}$ Department of Foundry, Politeknik Manufaktur Ceper, Klaten, Indonesia \\ 2 Department of Mechanical Engineering, Faculty of Engineering, Universitas Sebelas Maret, Surakarta, Indonesia
}

\section{$P A P E R \quad I N F O$}

Paper history:

Received 25 February 2021

Accepted in revised form 28 August 2021

Keywords:

Bulb turbine

Pico scale hydropower

Propeller

Water system

\section{$\begin{array}{lllllllll}A & B & S & T & R & A & C & T\end{array}$}

Water systems such as pipelines, pumping stations and other channels in horizontal flow have the potential as pico scale hydropower. This study aims to observe the effect of the number of blades and the blade angle on the electric power generation in the small bulb turbine on horizontal flow. This study also observes how the number of blades and blade angle affected the electrical power generated using analysis of variance. The level on the parameter number of blades used was 4, 5, 6, and 7 blades, while the level parameters on the blade angle were 15, 20, 25 , and 30 degrees and each level was tested 4 replication at the discharge of $13 \mathrm{~L} / \mathrm{s}$. This paper shows the results of turbine performance in the form of angular velocity, electric power, efficiency, and the test results of the analysis of variance using SPSS 17 software. The results of the study show the number of blades 5 with a 20 degree blade angle of the best performance compared another the number of blades and the blade angle with an efficiency of about $50 \%$. The results of the analysis of variance show the blade angle of the blade has a more dominant effect on electrical power than the number of blades.

doi: $10.5829 /$ ijee.2021.12.03.06

\section{INTRODUCTION}

Energy is a necessary sector for support human activities, such as education, health [1], infrastructural growth and economic development [2]. In developing countries, efforts to reduce air pollution are carried out by gradually shifting the use of fossil energy to alternative energy that is environmentally friendly [3] and sustainable [4]. Hydropower is one of the several types of alternative energy that is often found and that's air pollution free [5]. Research on small hydropower is currently focusing on differences in height or head from 2 to 30 meters, but for the head 0 to 2 meters or we called ultra-low head (ULH) undevelop. The development of turbine design, simple building, and economical, ULH hydropower becomes an attractive source of energy to be applied around the community [6].

Based on the power produced, hydropower is classified in several scales and the smallest scale is called pico hydro with a power that can be produced between 0 to $5 \mathrm{~kW}$ [7]. Pico scale hydropower potential can be obtained in water channels or water systems, including pumping stations, piping systems, drainage systems, and other channels [8]. One of the uses of the water system as a pico scale generator is the horizontal pipeline with propeller-type turbines as energy conversion devices $[8$, 9]. Propeller turbine is one type of reaction turbine that has many advantages including simple construction, low manufacturing costs, and can work with high efficiency values [10].

There are several types of propeller turbines, i.e tube turbine, starflo, Kaplan, and bulb turbine [10]. In horizontal flow tidal large power plants, bulb turbine shows better performance than other propeller types [11]. The bulb body on bulb turbine type locate before the runner in order to narrow the area of water flow, so the water velocity has increased [12].

An information about the effect of parameters on the desin of a water turbine provides the characteristics of the turbine so that an optimal turbine design is obtained [13].

*Corresponding Author Email: akhmadnurdin.89@gmail.com (A. Nurdin) 
Meanwhile, the characteristics and performance of vertical flow propeller turbines are influenced by several internal parameters [14], such as internal parameters include the number of blades [15] and the blade angle [16].

This study aims to determine the effect of the number of blades and the blade angle on the characteristics and electrical power on the bulb turbine on a horizontal flow pipeline in pico scale. Moreover, this study can be demonstrate the relationship between the number of blades with the blade angle, and can be also show as the variable that dominates in affect to the performance of the turbine in terms of electrical power. This research directly contributed to the development of design of hydroelectric power plant at horizontal flow in pico scale.

\section{EXPERIMENTAL}

The design of the turbine house in the study refers to research conducted by Zhu et al. [11] built on a smaller scale according to the ratio. The design of the propeller turbine curvature profile refers to the study conducted by Ramos et al. [8] with the tip diameter and turbine hubs of $8.48 \mathrm{~mm}$ and $2.56 \mathrm{~mm}$. Each parameter used 4 levels, i.e the number of blades 4, 5, 6 and 7 while on the blades angle 15, 20, 25, and 30 degrees each was tested at a discharge of $13 \mathrm{~L} / \mathrm{s}$. Propeller turbines were manufactured using 3D printing with material from Acrylonitrile Butadiene Styrene (ABS) as shown in Figure 1 with 6 the blade number on 15 degrees blade angle.

The sketch of rig test in this research is shown in Figure 2, using 2 pumps as circulating water from the reservoir. Discharge settings on $13 \mathrm{~L} / \mathrm{s}$ through the drain before entering the main pipe using a valve. The Large Angle Diffuser used to uniform the flow of water when entering the main pipe with a larger area. While the 3 -phase generator specifications are used 170 Watt at

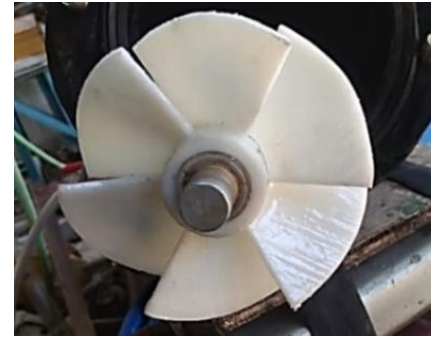

Figure 1. 3D printing propeller turbine with 6 blade and 15 degree

3500 optimal rotation. Measurement of the turbine shaft rotation uses an infrared tachometer while measuring the performance of the generator using a multitester with a 5 watt $\mathrm{AC}$ power load. The 3-phase converter circuit becomes 2 phases based on literature [17].

Table 1 summarized the research data (electric power) with two independent parameters i.e number of blades and blades angle of each of the four levels with four replication or also called 42 factorial design with replication. In data treatment according to Table 1 using the interval confidence value $(\alpha)$ of 0.05 or $95 \%$, then analyzes the significant test and dominant factors based on ANOVA data processing output univariate using SPSS Statistics 2017 software.

\section{RESULTS AND DISSCUSION}

\section{Turbine performance}

The results of the turbine bulb performance are shown in Figure 3. We can analysize the angular velocity, the generator power, and the efficiency. Based on Muller et al. [18] the water power is obtained by kinetic energy and mass flow rate $\left(\mathrm{P}_{\text {available }}=0.5 \rho \mathrm{Av}^{3}\right)$, so that the water power with turbine cross-sectional area and discharge of $13 \mathrm{~L} / \mathrm{s}$ in this study is 41.73 watt.

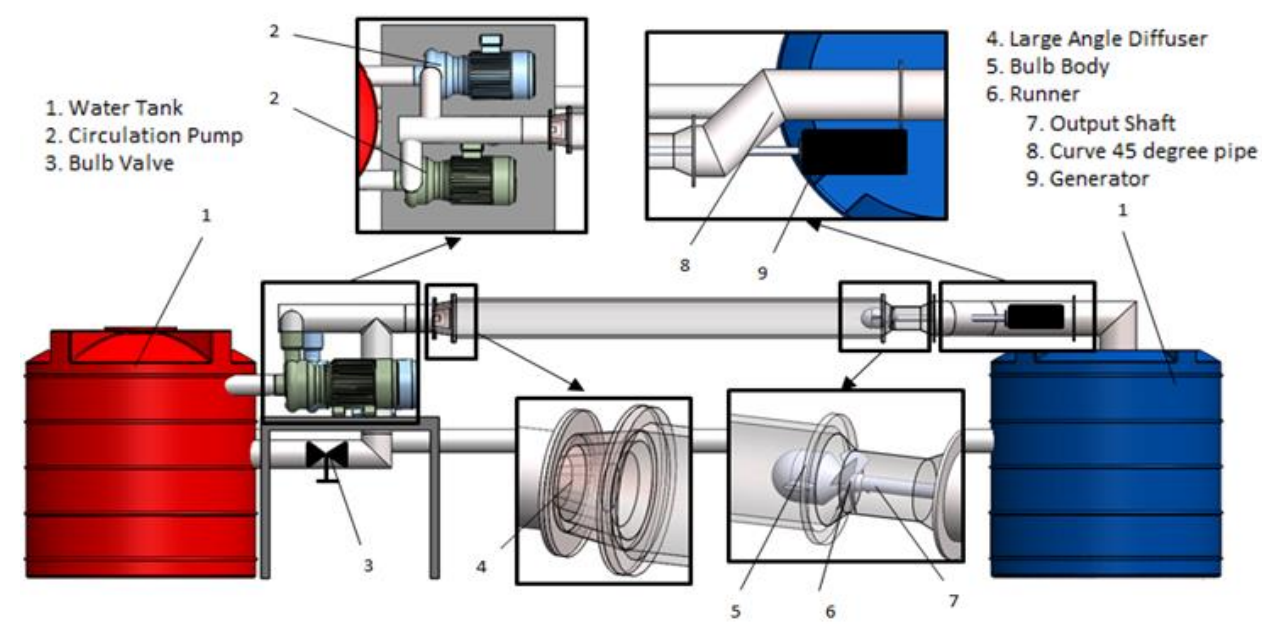

Figure 2. The sketch of rig test 
Table 1. Experimental result of electrical power (Watt)

\begin{tabular}{|c|c|c|c|c|c|c|c|c|}
\hline \multirow{2}{*}{ Number of blade } & \multicolumn{8}{|c|}{ Blade angle $\left(^{\circ}\right)$} \\
\hline & \multicolumn{2}{|c|}{15} & \multicolumn{2}{|c|}{20} & \multicolumn{2}{|c|}{25} & \multicolumn{2}{|c|}{30} \\
\hline \multirow{2}{*}{4} & 4.488 & 5.504 & 12.528 & 14.220 & 12.616 & 13.440 & 8.064 & 8.064 \\
\hline & 5.421 & 5.405 & 12.782 & 15.488 & 11.900 & 11.840 & 7.632 & 7.632 \\
\hline \multirow{2}{*}{5} & 6.820 & 6.900 & 20.435 & 23.166 & 18.492 & 18.632 & 11.938 & 11.938 \\
\hline & 6.552 & 8.000 & 19.110 & 23.400 & 17.485 & 19.500 & 11.938 & 11.938 \\
\hline \multirow{2}{*}{6} & 6.576 & 6.006 & 17.622 & 18.768 & 14.732 & 12.826 & 10.500 & 10.500 \\
\hline & 6.500 & 7.480 & 17.822 & 17.556 & 12.792 & 12.428 & 10.440 & 10.440 \\
\hline \multirow{2}{*}{7} & 4.500 & 4.116 & 11.245 & 12.075 & 6.600 & 6.510 & 5.376 & 5.376 \\
\hline & 4.687 & 4.180 & 11.375 & 11.725 & 6.201 & 6.560 & 5.405 & 5.405 \\
\hline
\end{tabular}

Figure $3 \mathrm{a}$ shows the curve of the effect of the blade angle on the angular velocity value. The curve shows the angular velocity value reaching its optimal point at 20 degrees, further increasing the degree of an angle the angular velocity value decreases. The blade angle will affect the inlet and outlet curvature of the blade, the greater the degree of the blade angle, the outlet curvature of the blade will be smaller. While if the curvature of the blade inlet and outlet getting smaller, the performance of the turbine will decrease. This is due to the greater degree of blade angle, the axial force received by the blade from the water will be smaller. But in this study at 15 degrees shows the angular velocity value is lower than 20 degrees. At 15 degrees, the received axial value is greater than 20 degrees, but the gap between blades at 15 degrees is getting narrower, so the water flow will be obstructed [1] and reduce the performance of the turbine.

Figure $3 \mathrm{a}$ also shows the number blades 5, the angular velocity is higher than another, the value of the angular velocity will decrease with the addition of the blade number i.e th 6 and 7 number of blades. At the number of blades more than 5 , the axial force received from the water flow to the turbine will increase, but the tangential force decreases [19]. At the number of blade more than 5, gaps between the blades become narrower so that the flow of water that passes through the blade will be increasingly hampered so that the performance of the turbine will decrease. Whereas the number of blades 4 shows the angular velocity value which is lower than the number of blades 5, this is due to the number of blades 4 axial forces received by the turbine are smaller and the water flow at the number of blades 4 and 5 is not obstructed, so the number of blades 5 showed the performance better than the number of blade 4 .

Figure $3 \mathrm{~b}$ shows the curve of the influence of the blade angle on the generator power (Watt), and this curve trend similar to the trend curve in Figure $3 \mathrm{a}$. The principle of the generator work converts mechanical power into electrical power when the rotor rotates, so the stator will cause an electric field and generate electricity, so if the

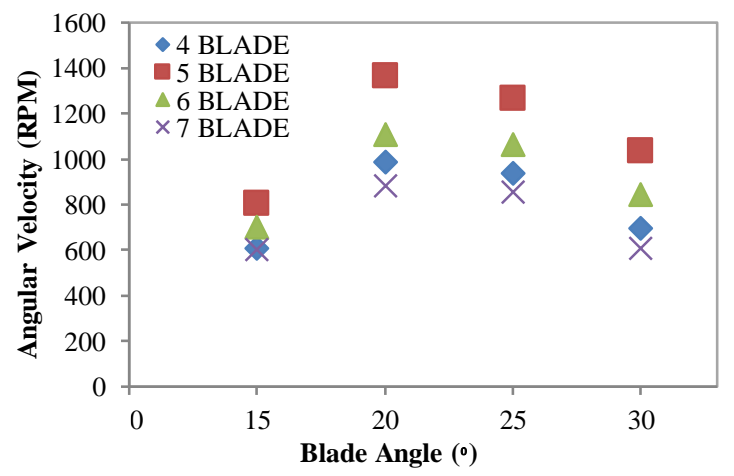

(a)

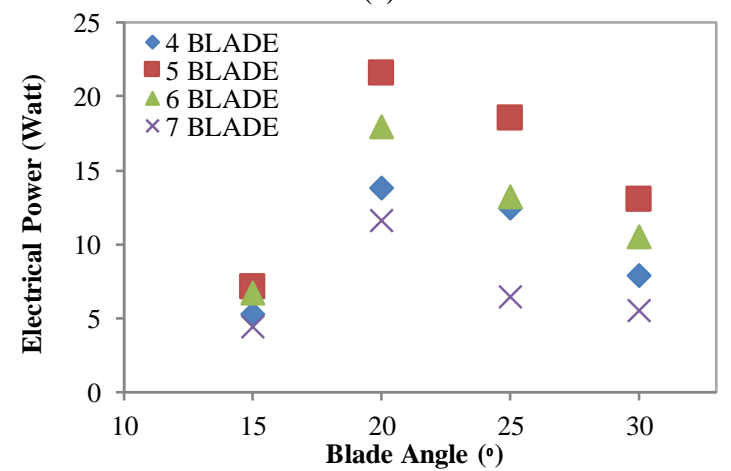

(b)

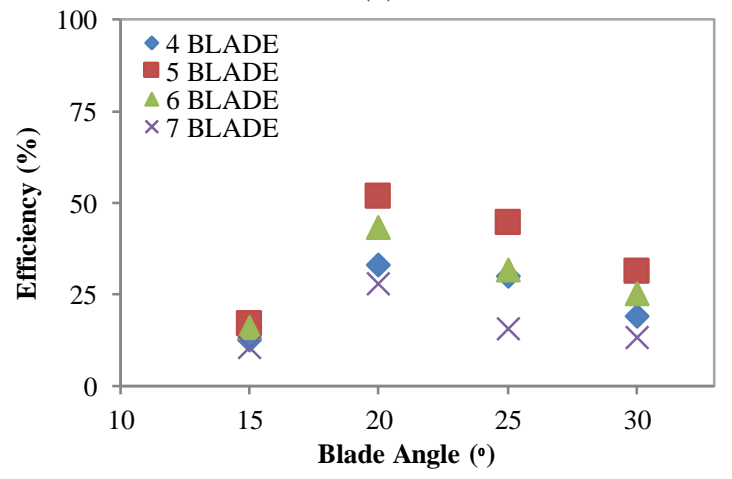

(c)

Figure 3. Relation between blade angle with (a) angular velocity, (b) electrical power, and (c) efficiency 
test load each parameter and level are the same (5 watts $\mathrm{AC})$, the angular velocity (rpm) value affects the performance. If the turbine rotates faster, the generator power is rising, because when the turbine rotates the generator rotor faster, the electric field produced by the rotor and stator also rising and the generator produces greater electrical power [20].

The number of blades and the blade angle directly affect the solidity value, while solidity is the ratio of stream-wise length (chord) and circumferential spacing (pitch) of the runner blade [21]. If the solidarity value rises, so the distance between the blades on the runner is getting narrower. Based on Brijkishore et al. (2020) research by computational fluid dynamic. The narrower of the distance between the blades, the velocity of the streamline at outlet area rises, this is shown in Figure 4 a the contour of the rises velocity if the number of blades increase, where the number of blades represents the narrower the gap between the blades. The rise of the velocity on streamline at the outlet side of the runner, the vortex increase (Figure $4 \mathrm{~b}$ ), and this increasing of the vortex cause the blocking effect at the flow of water, which further reduces the performance of the propeller water turbine.

Evaluation of the performance of a turbine can be seen from the value of the ratio between the available power and the power generated, or we call it efficiency. Figure $3 \mathrm{c}$ shows the highest efficiency value of this study reaching about $50 \%$ at 20 degrees with a number of blades of 5 , and slowly decreasing at 25 and 30 degrees. While the lowest efficiency value is shown at a slope of 15 degrees with a value that is far different than another degree angle, this is due to the turbine blade's 15 degree is not able to convert the available power properly.

\section{Analysis of variance (ANOVA)}

This section explains the effect of each independent parameter on the dependent parameter and explain the relationship between the dependent parameter. The test results show a significant effect if the significance value on the ANOVA test results is below the value of the confidence interval and in this study below 0.05 .

Table 2 summarized the results of ANOVA SPSS output with a significance result below 0.05 on the

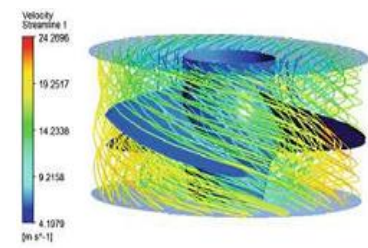

(a) 3-Blade

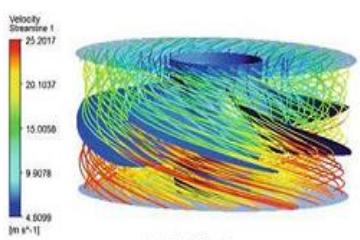

(c) 5-Blade
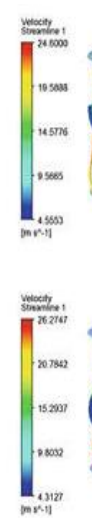

(a)

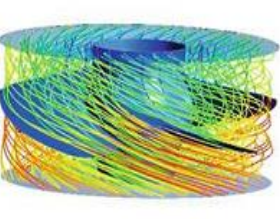

(b) 4-Blade

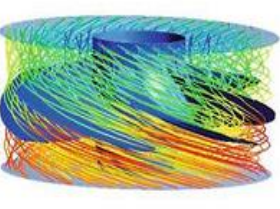

(d) 6-Blade

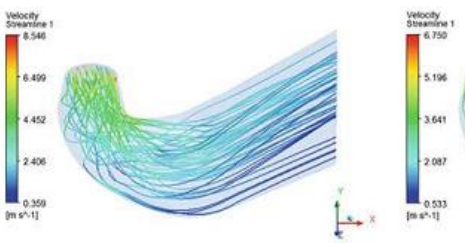

(a) 3-Blade

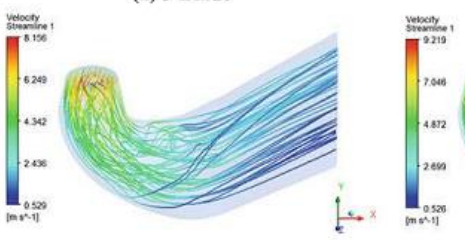

(c) 5-Blade

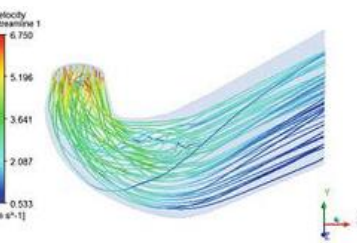

(b) 4-Blade

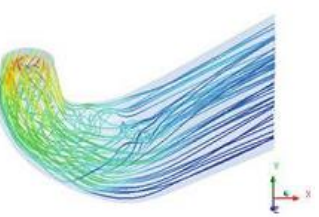

(d) 6-Blade

(b)

Figure 4. Sreamline in runner different solidity simulation at (a) runner (b) draftube [21]

Table 2. ANOVA SPSS result output

\begin{tabular}{lccccc}
\hline \multicolumn{4}{c}{ Tests of between-subjects effects dependent variable: electrial power } & & \\
\hline Source & Type III Sum of Squares & df & Mean Square & F & Sig. \\
\hline Corrected Model & $1629.625^{\text {a }}$ & 15 & 108.642 & 142.326 & 0.000 \\
Blade Angle & 958.742 & 3 & 319.581 & 418.665 & 0.000 \\
Number of Blade & 557.520 & 3 & 185.840 & 243.459 & 0.000 \\
Blade Angle * Number of Blade & 113.363 & 9 & 12.596 & 16.501 & 0.000 \\
Error & 36.640 & 48 & 0.763 & & \\
Total & 9371.703 & 64 & & & \\
Corrected Total & 1666.265 & 63 & & & \\
\hline
\end{tabular}

a. R Squared $=0.978$ (Adjusted R Squared $=0.971)$ 
number of blades, the blade angle, and interactions of both. This shows that each level of each independent parameters (number of blades and blade angle) has a significant effect on the dependent value parameter (electric power). Based on the F-value the blade angle parameter is a more dominant effect on the dependent parameter compared to the parameter number of blades turbine.

Table 2 also states the corelation between the independent parameters and the dependent parameter from R Squared value, If the value of R Squared gets closer to 1 so the corelation gets stronger. In this ANOVA test, the R Squared value of 0.978 shows a very strong relationship between the independent parameters (number of blades, blade angle, and number of blades*blade angle) and dependent parameter (electric power) [22].

\section{CONCLUSIONS}

Data, analysis of experimental tests and ANOVA tests are presented in this paper. Based on the results of testing with the blade number 5 and 20 degrees blade angle shows the best performance compared to the number of blades and another blade angle. This study also shows the blade angle is more dominant effect to the electric power than the number of blade, besides that there is a very strong correlation between independent and dependent parameters. With the efficiency value (power available for electrical power) reaching $50 \%$, the design of a small bulb turbine water is feasible to be applied to the community.

Based on the results of the ANOVA test, this study contributes that the blade angle parameter has more influence on the performance of the propeller turbine than the number of blades, so that in designing the propeller turbine especially in horizontal flow, the blade angle parameter must be considered.

\section{REFERENCES}

1. Belay, A. K., Atenafu, D., Birhan, S. and Tegengn, T. 2020 "Techno-economic Feasibility Study of the Gunde Teklehaymanote Micro-hydropower Plant at Tindwat River, Central Gondar, Ethiopia." Iranian Journal of Energy and Environment, $11(2), \quad$ pp.130-136. https://doi.org/10.5829/IJEE.2020.11.02.06

2. Olanrewaju, R. M., Olatunji, O. W. and Akpan, G. P. 2018. "Impacts of Climate Variability on Hydroelectric Power Generation in Shiroro Station, Nigeria." Iranian Journal of Energy and Environment, 9(3), pp.197-203. https://doi.org/10.5829/IJEE.2018.09.03.07

3. Belay, A. 2019. "Current Status, Future Potential and Barriers for Renewable Energy Development in Ethiopia (Short Communication)." Iranian Journal of Energy and Environment, 10(4). https://doi.org/10.5829/IJEE.2019.10.04.07
4. Alnakhlani, M. M., Mukhtar, M., Himawanto, D. A., Alkurtehi, A. and Danardono, D. 2014. "Effect of the Bucket and Nozzle Dimension on the Performance of a Pelton Water Turbine." Modern Applied Science, 9(1), pp.25-33. https://doi.org/10.5539/mas.v9n1p25

5. Nurhayati, B. and Himawanto, D. A. 2018. "A renewable energy potential Pyrolysis Sengon (Paraserianthe falcatari) as a Renewable Energy Potential." AIP Conference Proceedings, 2049(1). https://doi.org/10.1063/1.5082437

6. Zhou, D. and Deng, Z. D. 2017. "Ultra-low-head hydroelectric technology: A review." Renewable and Sustainable Energy Reviews, 78, pp.23-30. https://doi.org/10.1016/j.rser.2017.04.086

7. Ho-Yan, B. 2012. Design of a Low Head Pico Hydro Turbine for Rural Electrification in Cameroon. The University of Guelph.

8. Ramos, H. M., Simão, M. and Kenov, K. N. 2012. "Low-Head Energy Conversion: A Conceptual Design and Laboratory Investigation of a Microtubular Hydro Propeller." ISRN Mechanical Engineering, 2012, pp.1-10. https://doi.org/10.5402/2012/846206

9. Ramos, H. M., Simão, M. and Borga, A. 2013. "Experiments and CFD Analyses for a New Reaction Microhydro Propeller with Five Blades." Journal of Energy Engineering, 139(2), pp.109117. https://doi.org/10.1061/(ASCE)EY.1943-7897.0000096

10. Elbatran, A. H., Yaakob, O. B., Ahmed, Y. M. and Shabara, H. M. 2015. "Operation, performance and economic analysis of low head micro-hydropower turbines for rural and remote areas: A review." Renewable and Sustainable Energy Reviews, 43, pp.40-50. https://doi.org/10.1016/j.rser.2014.11.045

11. Zhu, L., Zhang, H. P., Zhang, J. G., Meng, X. C. and Lu, L. 2012. "Performance of a bulb turbine suitable for low prototype head: model test and transient numerical simulation." IOP Conference Series: Earth and Environmental Science, 15(4), pp.042032. https://doi.org/10.1088/1755-1315/15/4/042032

12. Luo, Y., Wang, Z., Liu, X., Xiao, Y., Chen, C., Wang, H. and Yan, J. 2015. "Numerical prediction of pressure pulsation for a low head bidirectional tidal bulb turbine." Energy, 89, pp.730-738. https://doi.org/10.1016/j.energy.2015.06.022

13. Balaka, R., Rachman, A. and Delly, J. 2014. "Blade Number Effect for A Horizontal Axis River Current Turbine at A Low Velocity Condition Utilizing A Parametric Study with Mathematical Model of Blade Element Momentum." Journal of Clean Energy Technologies, 2(1), pp.1-5. https://doi.org/10.7763/JOCET.2014.V2.79

14. Singh, P. and Nestmann, F. 2010. "Exit blade geometry and partload performance of small axial flow propeller turbines: An experimental investigation." Experimental Thermal and Fluid $\begin{array}{lll}\text { Science, } & \text { 34(6), pp.798-811. }\end{array}$ https://doi.org/10.1016/j.expthermflusci.2010.01.009

15. Byeon, S. and Kim, Y. 2013. "Influence of Blade Number on the Flow Characteristics in the Vertical Axis Propeller Hydro Turbine." International Journal of Fluid Machinery and Systems, 6(3), pp.144-151. https://doi.org/10.5293/IJFMS.2013.6.3.144

16. Shantika, T. 2013. "Perekayasaan Pembangkit Listrik Tenaga Air Untuk Penyediaan Listrik Skala Kecil 100 Watt." Journal of Industrial Research Jurnal, 7(2), pp.137-146. (In Indonesian)

17. Ekanayake, J. B. 2002. "Induction generators for small hydro schemes." Power Engineering Journal, 16(2), pp.61-67. https://doi.org/10.1049/pe:20020202

18. Muller, M. W., Rue, Z. and Hiebler, K. 2016. "Investigation of the Potential Use of Tidal Current Turbines in the Ocean City, Maryland Inlet for Renewable Energy Generation." Smart Grid and Renewable Energy, 07(04), pp.142-146. https://doi.org/10.4236/s gre.2016.74010

19. Singh, P. and Nestmann, F. 2011. "Experimental investigation of the influence of blade height and blade number on the performance 
of low head axial flow turbines." Renewable Energy, 36(1), pp.272-281. https://doi.org/10.1016/j.renene.2010.06.033

20. Kurniawan, R., Himawanto, D. A. and Widodo, P. J. 2019. "The performance of numbers of blade towards picohydro propeller turbine." IOP Conference Series: Materials Science and Engineering, 508, pp.012057. https://doi.org/10.1088/1757$899 X / 508 / 1 / 012057$
21. Brijkishore, Khare, R. and Prasad, V. 2020. "Performance Evaluation of Kaplan Turbine with Different Runner Solidity Using CFD." Advances in Intelligent Systems and Computing (pp. 757-767). Springer Nature Singapore Pte Ltd. https://doi.org/10.1007/978-981-13-8196-6_67

22. Jonathan Sarwono. 2006. Analisis Data Penelitian Menggunakan SPSS 13 (1st edition). Yogyakarta: Penerbit Andi.

\section{COPYRIGHTS}

(C)2021 The author(s). This is an open access article distributed under the terms of the Creative Commons Attribution (CC BY 4.0), which permits unrestricted use, distribution, and reproduction in any medium, as long as the original authors and source are cited. No permission is required from the authors or the publishers.

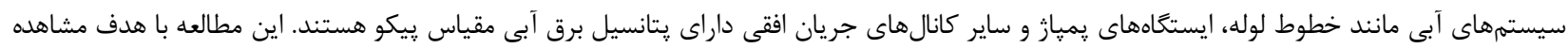

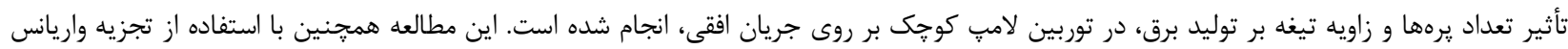

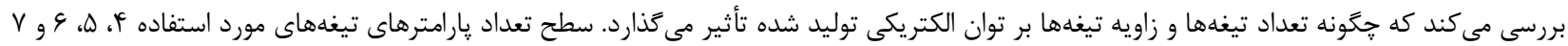

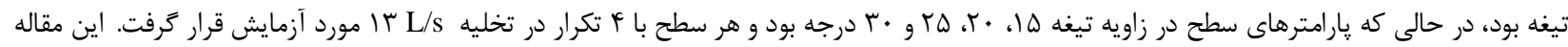

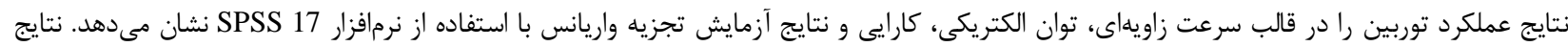

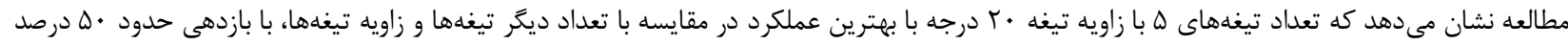

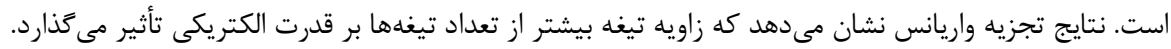

